Check for updates

Cite this: RSC Adv., 2019, 9, 13757

\title{
Efficient resolution of 3-aryloxy-1,2-propanediols using CLEA-YCJ01 with high enantioselectivity $\dagger$
}

\begin{abstract}
Bin Wang, (iD ${ }^{\text {ab }}$ Bin $\mathrm{Wu}^{\mathrm{a}}$ and Bingfang $\mathrm{He}^{\text {*a }}$
The lipase YCJ01 from Burkholderia ambifaria is an organic solvent-stable enzyme and its activity can be activated by a hydrophobic solvent due to the "interface activation" mechanism. The activity of lipase YCJ01 increased by 2.1-fold with $t$-butanol as the precipitant even after cross-linking. The cross-linked enzyme aggregates of lipase YCJ01 (CLEAs-YCJ01) were found to be efficient for resolving 3-(4methylphenoxy)-1,2-propanediol (MPPD) through sequential esterification. Excellent enantioselectivity towards MPPD ( $E>400$ ), excellent enantiomeric excess (ee) values of $99.2 \%$ for $S$-diacetates and $99.1 \%$ for $R$-monoacetate, and high yield $(49.9 \%)$ were achieved using a high substrate concentration $\left(180 \mathrm{mmol} \mathrm{L}^{-1}\right)$. Thus, $R$ - and $S$-type compounds with excellent ee values were simultaneously obtained, and MPPD was resolved by CLEAs-YCJ01. CLEAs-YCJ01 also showed high operational stability and maintained $91.2 \%$ residual activity after ten batches. To further evaluate the substrate specificity of CLEAs-YCJ01, a series of 3-aryloxy-1,2-propanediols (six analogues of MPPD) was applied as substrates for resolution. Under the optimized reaction conditions of reaction temperature of $35{ }^{\circ} \mathrm{C}$, MPPD concentration of $180 \mathrm{mmol} \mathrm{L}^{-1}$, molar ratio of vinyl acetate to MPPD of $3: 1$, and isopropyl ether as the solvent, CLEAs-YCJ01 exhibited relatively strict enantioselectivity towards all the analogues of MPPD with a high yield $(\geq 49.3 \%)$, favourable ee values $(94.8-99.4 \%)$ for $S$-diacetates, and high ee values (92.1$99.2 \%)$ for $R$-monoacetate, which shows potential prospects for industrial applications.
\end{abstract}

Received 12th February 2019
Accepted 14th March 2019

DOI: 10.1039/c9ra01103j

rsc.li/rsc-advances preparation of chiral APPDs, namely enzymatic methods, is becoming increasingly attractive. Several epoxides at a $10 \mathrm{mM}$ concentration were resolved to produce $S$-3-benzoxyl-1,2propanediols using an epoxide hydrolase derived from Aspergillus niger, ${ }^{8}$ and the enantioselectivity values ranged between 22 and 60 after $2 \mathrm{~h}$. In another study, a recombinant epoxide hydrolase from Yarrowia lipolytica ${ }^{9}$ was applied as a catalyst for the preparation of $S$-3-phenoxy-1,2-propanediols, and the ee values of the products were $95 \%$. However, water-dependent side reactions such as the non-catalytic hydrolysis of epoxides resulted in a decrease in the ee value and yield of the product. ${ }^{10,11}$ On the other hand, most epoxide hydrolases preferentially hydrolyze racemic epoxides into the $S$ configuration of the formed diol, which limits their applications in the preparation of $R$-type diols.

Lipases (esterases) are often applied for the synthesis, hydrolysis, and transesterification of esters and exhibit enantioselective properties. ${ }^{12}$ For example, the dicarboxyesters of 1,2propanediols were sequentially hydrolyzed by an esterase ${ }^{13}$ to obtain $(S)$-1-phenyl-1,2-ethanediol with an ee of 96\%. Also, chiral 3-aryloxy-1,2-propanediols can be directly obtained through sequential esterification with a lipase. Theil's group ${ }^{\mathbf{1 4 , 1 5}}$ used Amano lipase PS to separate 3-aryloxy-1,2-propanediols, yielding $R$-type and $S$-type compounds with ee values in the range of $55-99.8 \%$ and $79-96.8 \%$, respectively, resulting in moderate enantioselectivity towards the $S$-type compounds. The
${ }^{a}$ College of Biotechnology and Pharmaceutical Engineering, Nanjing Tech University, Nanjing 211816, China. E-mail: bingfanghe@njut.edu.cn

${ }^{b}$ School of Chemistry \& Environmental Engineering, Jiangsu University of Technology, Changzhou 213001, China

$\dagger$ Electronic supplementary information (ESI) available. See DOI: 10.1039/c9ra01103j 
lipase PS is hard to apply in the preparation of $S$-type compounds.

The immobilization of the enzyme affords improved operational stability and allows its facile separation and reuse. ${ }^{16}$ Thus, effective methodologies for enzyme immobilization as CLEAs (cross-linked enzyme aggregates) are applicable to a broad range of enzymes, and CLEAs are proven to be significantly more stable to denaturation by heat, organic solvents and proteolysis than the corresponding soluble enzyme or lyophilized (freeze-dried) powder. ${ }^{17}$ In this work, CLEAs of lipase YCJ01 from Burkholderia ambifaria ${ }^{\mathbf{1 8}}$ (CLEAs-YCJ01) were prepared and evaluated for the resolution of 3-(4methylphenoxy)-1,2-propanediol (MPPD). CLEAs-YCJ01 showed strict enantioselectivity towards MPPD and excellent ee values were simultaneously obtained for both $R$ - and $S$-type compounds. A series of 3-aryloxy-1,2-propanediols was also used to evaluate the substrate specificity of CLEAs-YCJ01.

\section{Results and discussion}

\section{Selection of precipitating agent for preparation of CLEAs-YCJ01}

The selection of an appropriate precipitating agent is very important for the preparation of CLEAs-YCJ01. According to the previous study on the stability of lipase YCJ01 in various organic solvents $(25 \%, \mathrm{v} / \mathrm{v})$ by Yao, $^{18}$ the lipase YCJ01 is stable in ethanol, 1-propyl alcohol, 2-propyl alcohol, $t$-butanol and acetone. In addition, the commonly used protein precipitant, saturated ammonium sulfate solution, was considered. Therefore, these solvents were selected as the precipitants in our present study. Their effects on the activity recovery of CLEAs-
YCJ01 are shown in Table 1. The type of precipitant used has a great influence on the activity recovery of CLEAs-YCJ01. When saturated ammonium sulfate solution was used as the precipitant, the activity recovery of CLEAs-YCJ01 was 77.9\%; however, when the precipitant was changed to organic solvents, the activity recovery of CLEAs-YCJ01 was higher than 100\%. Specially, $214.8 \%$ of activity recovery was achieved using $t$ butanol as the precipitant. These results may be closely related to the "interface activation" mechanism of lipase. Most lipases have an activity center featuring an $\alpha$-helical amphipathic "lid". ${ }^{19}$ In a hydrophobic environment or on an oil-water interface, the lid is opened outwards from the active center so that it does not hinder the entry of the substrate into the active center and the lipase shows an active form. In this study, the organic solvents used as precipitants could trigger the "interface activation" mechanism. In the solvent $t$-butanol with higher hydrophobicity, the activity of lipase YCJ01 may be activated efficiently and the active form was kept after crosslinking. Moreover, the solvent $t$-butanol with higher hydrophobicity may induce the aggregation of enzyme proteins in a shorter time, which reduced the loss of enzymatic activity. ${ }^{20}$

Glutaraldehyde is the most commonly used cross-linker for the preparation of CLEAs. The effect of glutaraldehyde concentration on the activity recovery of CLEAs-YCJ01 is shown in Table 2. As the glutaraldehyde concentration increased from $0.05 \%(\mathrm{v} / \mathrm{v})$ to $0.25 \%(\mathrm{v} / \mathrm{v})$, the activity recovery reached a high level $(214.8 \%)$. Further increasing the amount of glutaraldehyde caused a great loss in the activity of CLEAs-YCJ01 and a low activity recovery. Therefore, $0.25 \%$ was selected as the optimum glutaraldehyde amount.

Table 1 Special activity and activity recovery of CLEAs-YCJ01 in different precipitants ${ }^{c}$

\begin{tabular}{lcr}
\hline Precipitant & Specific activity ${ }^{a}\left(\times 10^{4} \mathrm{U} \mathrm{g}^{-1}\right)$ & Activity recovery $^{b}(\%)$ \\
\hline Ethanol & & $100.6 \pm 4.6$ \\
1-Propanol & $4.44 \pm 0.20$ & $119.1 \pm 6.9$ \\
2-Propanol & $5.26 \pm 0.30$ & $127.5 \pm 5.5$ \\
Acetone & $5.63 \pm 0.24$ & $109.3 \pm 7.2$ \\
$t$-Butanol & $4.83 \pm 0.32$ & $214.8 \pm 8.3$ \\
Saturated ammonium sulfate & $10.86 \pm 0.37$ & $77.9 \pm 3.8$
\end{tabular}
solution

${ }^{a}$ Special activity $=($ activity in the CLEAs/weight of CLEAs $) \times 100 \% .{ }^{b}$ Activity recovery $=($ activity in the CLEAs/activity of lipase solution used $) \times$ $100 \%$. ${ }^{c}$ Conditions: protein concentration of enzyme solution: $4.0 \mathrm{mg} \mathrm{mL}^{-1}$, activity of lipase YCJ01: $176.6 \mathrm{U} \mathrm{mL}^{-1}$, volume of precipitant : volume of enzyme solution $=3: 1$, cross-linking time $=4 \mathrm{~h}$ and glutaraldehyde amount $=0.25 \%(\mathrm{v} / \mathrm{v}, \%)$.

Table 2 Effect of the amount of glutaraldehyde on CLEAs-YCJ01 activity

\begin{tabular}{lcc}
\hline Amount $^{a}(\mathrm{v} / \mathrm{v}, \%)$ & Specific activity $^{a}\left(\times 10^{4} \mathrm{U} \mathrm{g}^{-1}\right)$ & Activity recovery $^{b}(\%)$ \\
\hline 0.05 & $13.02 \pm 0.46$ & $165.8 \pm 10.4$ \\
0.15 & $11.87 \pm 0.28$ & $192.3 \pm 6.3$ \\
0.2 & $11.53 \pm 0.37$ & $211.3 \pm 8.4$ \\
0.25 & $10.86 \pm 0.37$ & $214.8 \pm 8.3$ \\
0.3 & $9.99 \pm 0.37$ & $202.8 \pm 8.4$ \\
0.35 & $7.97 \pm 0.48$ & $166.4 \pm 10.8$ \\
0.375 & $6.12 \pm 0.41$ & $130.0 \pm 9.3$
\end{tabular}

${ }^{a}$ Amount of glutaraldehyde $=$ glutaraldehyde volume/enzyme volume $\times 100 \% .{ }^{b}$ Reaction conditions: enzyme protein concentration $=4.0 \mathrm{mg}$ $\mathrm{mL}^{-1}$, activity of enzyme solution $=176.6 \mathrm{U} \mathrm{mL}^{-1}$, volume of $t$-butanol $:$ volume of enzyme $=3: 1$, and cross-linking time $=4 \mathrm{~h}$. 

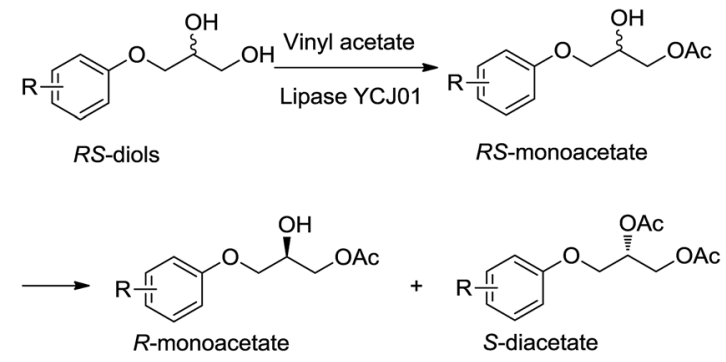

$\mathrm{R}=\mathrm{H}(1) ; 4-\mathrm{MeO}(2) ; 2-\mathrm{MeO}(3) ; 2-\mathrm{Me}(4) ; 3-\mathrm{Me}(5) ; 4-\mathrm{Me}$ (6)

Scheme 1 Enzymatic resolution of racemic 3-aryloxy-1,2propanediols.

\section{Optimization for the resolution of MPPD by CLEAs-YCJ01}

As shown in the Scheme 1, the reaction was carried out with vinyl acetate in the presence of CLEAs-YCJ01. 3-(4Methylphenoxy)-1,2-propanediol (MPPD, substrate 2) was firstly formed into primary monoacetate, and the formed monoacetate was enantioselectively converted into the $S$-diacetates. In the next experiment, the conditions of resolution were optimized to improve the reaction rate and ee values.

The effect of organic solvents on the resolution of MPPD. In non-aqueous enzymology, medium engineering is an effective means to control and regulate the structure and function of enzymes. ${ }^{21}$ Thus, the effects of six solvents with different hydrophobicities ( $\log P, n$-hexane/water distribution coefficient) on the activity and enantioselectivity of CLEAs-YCJ01 were investigated. As shown in Table 3 , in the moderately hydrophobic isopropyl ether, the conversion of MPPD reached 49.1\%; however, in the hydrophilic solvents tetrahydrofuran (THF) and acetone, the conversions were $41.6 \%$ and $43.2 \%$, respectively. In the hydrophilic solvents, the "critical water" layer at the enzymatic surface is stripped off by the solvent, ${ }^{22}$ resulting in an increase in the rigidity of the enzyme structure and a decrease in its reaction activity. In isopropyl ether, the "critical water" layer on the enzymatic surface was maintained, which favored the flexibility of the enzyme, and thus the enzyme retained its high activity. Meanwhile, in hexane and toluene with higher hydrophobicity, the activity of CLEAs-YCJ01 decreased, which may be because these highly hydrophobic solvents altered the microenvironment of the active center, which hindered the proper orientation of the substrates in the active center and led to a reduction in the reaction rate. ${ }^{23}$ Thus, a solvent with moderate hydrophobicity is beneficial to maintain the "critical water" of the enzymatic surface and also facilitate the proper orientation of substrates in its active center.

The values of ee for the $S$-diacetates were determined and also presented in Table 3. The solvents markedly affected the enantioselectivity of CLEAs-YCJ01. Fortunately, in isopropyl ether, CLEAs-YCJ01 not only showed the highest activity, but also the highest enantioselectivity towards MPPD. When the hydrophobic solvents hexane and toluene were used as solvents, the enantioselectivity was 126 and 89, respectively. When diisopropyl ether was used as the solvent, the enantioselectivity rapidly increased to 1190 . However, upon changing the solvents to the hydrophilic solvents $t$-butanol, THF and acetone, the enantioselectivity decreased to 105, 24 and 37, respectively. Clearly, isopropyl ether proved to be the most suitable solvent for the resolution of MPPD through transesterification. Isopropyl ether also favored the Penicillium roqueforti lipase ${ }^{24}$ and porcine pancreatic lipase, ${ }^{25}$ which exhibited the best catalytic performances for the resolution of secondary alcohols through transesterification. However, the reason for these lipases showing their best catalytic performances in isopropyl ether is unclear. The enantioselectivity of lipases may change, sometimes dramatically, as a function of the nature of the solvents and for other reasons. ${ }^{26}$

Effect of the molar ratio of vinyl acetate to MPPD on the resolution of MPPD. The molar ratio of vinyl acetate to MPPD is a key factor in the industrial application of enzymes. Thus, its effects on the conversion and enantioselectivity were investigated and the results are shown in Table 4 . When the molar ratio of vinyl acetate to MPPD was increased from $2: 1$ to $3: 1$, the conversion of MPPD increased rapidly from $40.1 \%$ to $49.3 \%$ in $9 \mathrm{~h}$. This is because an increased abundance of acyl donors will contribute to the formation of acyl-enzyme intermediates, thus speeding up the reaction rate. ${ }^{27}$ With a further increase in the molar ratio of vinyl acetate to MPPD, there was no further increase in the conversion and the $E$-values still maintained a high level $(E>400)$. This means that an abundance of acyl donors does not alter the enantioselectivity of CLEAs-YCJ01 to MPPD. Therefore, the appropriate molar ratio of vinyl acetate to MPPD is $3: 1$.

Table 3 Resolution of racemic MPPD in non-aqueous solvents

\begin{tabular}{|c|c|c|c|c|c|c|}
\hline Catalyst & Solvent & $\log P$ & Initial rates $\left(\mu \mathrm{mol} \min ^{-1}\right)$ & ee of $S$-diacetates & $c(\%)$ & $E^{a}$ \\
\hline \multirow[t]{3}{*}{ Lipase YCJ01 } & Diisopropyl ether & 1.9 & $67.2 \pm 1.9$ & $99.1 \pm 0.1$ & $40.4 \pm 1.2$ & $406 \pm 23$ \\
\hline & $t$-Butanol & 0.6 & $51.1 \pm 2.3$ & $94.6 \pm 0.4$ & $33.4 \pm 1.5$ & $58 \pm 3$ \\
\hline & Acetone & -0.23 & $41.6 \pm 2.2$ & $82.7 \pm 0.5$ & $30.1 \pm 1.6$ & $15 \pm 2$ \\
\hline \multirow[t]{2}{*}{ CLEAs-YCJ01 } & Diisopropyl ether & 1.9 & $81.8 \pm 0.2$ & $99.7 \pm 0.1$ & $49.1 \pm 0.1$ & $1190 \pm 35$ \\
\hline & $t$-Butanol & 0.6 & $74.2 \pm 1.3$ & $97.1 \pm 0.4$ & $44.6 \pm 0.8$ & $105 \pm 5$ \\
\hline
\end{tabular}

${ }^{a} E=\ln \left[(1-c)\left(1-\mathrm{ee}_{\mathrm{s}}\right) /(1-c)\left(1+\mathrm{ee}_{\mathrm{s}}\right)\right]$, reaction conditions: $50 \mathrm{mM}$ MPPD and $100 \mathrm{mM}$ vinyl acetate was catalyzed in $20 \mathrm{~mL}$ solvent containing $20 \mathrm{mg}$ of CLEAs-YCJ01, the mixture was incubated at $30^{\circ} \mathrm{C}$ and rotated at $180 \mathrm{rpm}$, and the reaction time was $12 \mathrm{~h}$. 
Table 4 Effect of molar ratio of vinyl acetate to MPPD on conversion and enantioselectivity

\begin{tabular}{|c|c|c|c|c|}
\hline \multirow[b]{2}{*}{ Molar ratio } & \multicolumn{2}{|l|}{ ee } & \multirow[b]{2}{*}{$c(\%)$} & \multirow[b]{2}{*}{$E^{a}$} \\
\hline & $R$-Monoacetate & $S$-Diacetates & & \\
\hline $2: 1$ & $66.6 \pm 0.3$ & $99.7 \pm 0.1$ & $40.1 \pm 0.2$ & $730 \pm 30$ \\
\hline $2.5: 1$ & $85.2 \pm 0.2$ & $99.6 \pm 0.1$ & $46.1 \pm 0.2$ & $900 \pm 30$ \\
\hline $3: 1$ & $96.4 \pm 0.2$ & $99.4 \pm 0.1$ & $49.3 \pm 0.2$ & $1672 \pm 40$ \\
\hline $3.5: 1$ & $96.1 \pm 0.2$ & $99.3 \pm 0.1$ & $49.2 \pm 0.1$ & $1220 \pm 35$ \\
\hline $4: 1$ & $96.5 \pm 0.2$ & $99.4 \pm 0.1$ & $49.2 \pm 0.1$ & $1114 \pm 35$ \\
\hline
\end{tabular}

${ }^{a} E=\ln \left[(1-c)\left(1-\mathrm{ee}_{\mathrm{s}}\right) /(1-c)\left(1+\mathrm{ee}_{\mathrm{s}}\right)\right]$, reaction conditions: $50 \mathrm{mM}$ MPPD was catalyzed in $20 \mathrm{~mL}$ isopropyl ether containing $20 \mathrm{mg}$ CLEAs-YCJ01, the mixture was incubated at $30{ }^{\circ} \mathrm{C}$ and rotated at $180 \mathrm{rpm}$. The reaction time was $9 \mathrm{~h}$.

The effect of temperature on the resolution of MPPD. The effect of temperature on the enzymatic reaction was investigated and the results are shown in Fig. 1 . The catalytic activity increased from 42.6 to $68.2 \mu \mathrm{mol}(\mathrm{min} \mathrm{g})^{-1}$ in the range of 30 $50{ }^{\circ} \mathrm{C}$. However, when the temperature exceeded $35^{\circ} \mathrm{C}$, the ee values of $S$-diacetates decreased to below 99\%. High temperature conditions change the structure of the catalytic center of lipases ${ }^{28}$ which explains the reduction in the enantioselectivity of CLEAs-YCJ01 towards MPPD at high temperatures. Thus, the optimum reaction temperature was determined to be $35{ }^{\circ} \mathrm{C}$.

The effect of the water content of the solvent on the resolution of MPPD. As shown in Fig. 2, CLEAs-YCJ01 showed high catalytic activity when the water content was between 0.56 and 0.75 , and the conversion reached more than $49 \%$ at $3 \mathrm{~h}$. However, the conversion at $3 \mathrm{~h}$ was less than $42 \%$ at the low water contents of $0.11,0.24$, and 0.33 . Additionally, the ee values of the $S$-diacetates decreased slightly to $98.2 \%$ at a water content of 0.75 . The above results indicated that a high water content improved the flexibility and catalytic activity of CLEAs-YCJ01 while decreasing its enantioselectivity, ${ }^{29}$ leading to a decrease in the ee values of $S$-diacetates. Therefore, the appropriate water content is 0.56 .

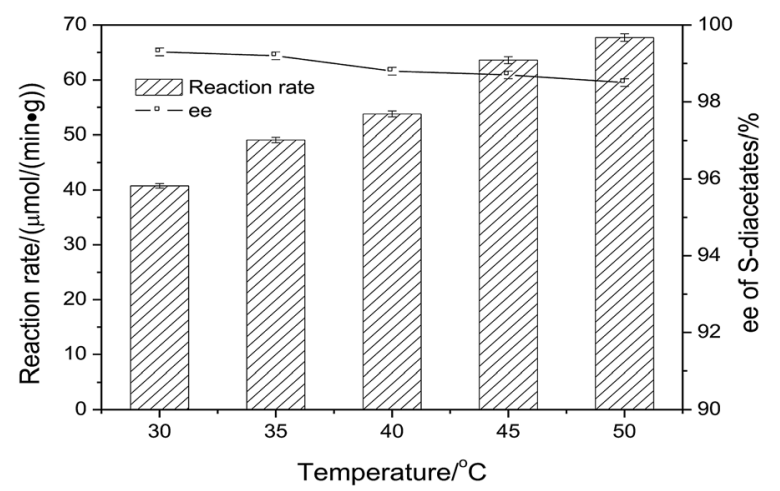

Fig. 1 Effect of temperature on the resolution of MPPD. Reaction conditions: the resolution of MPPD was performed in $20 \mathrm{~mL}$ isopropyl ether containing $50 \mathrm{mM}$ MPPD, $100 \mathrm{mM}$ vinyl acetate and $20 \mathrm{mg}$ CLEAs-YCJ01. The mixture was rotated at $180 \mathrm{rpm}$ and the reaction time was $6 \mathrm{~h}$.

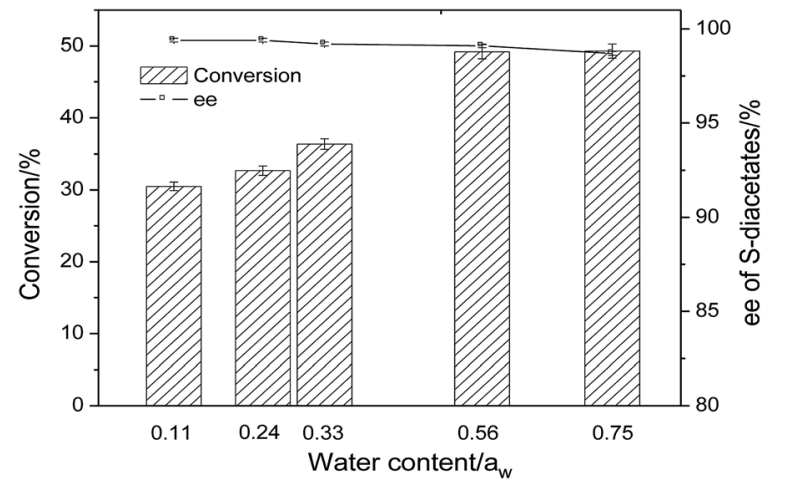

Fig. 2 Effect of water content on the resolution of MPPD. Reaction conditions: the resolution of MPPD was performed in $20 \mathrm{~mL}$ isopropyl ether containing $50 \mathrm{mM}$ MPPD, $150 \mathrm{mM}$ vinyl acetate and $20 \mathrm{mg}$ CLEAs-YCJ01. The mixture was incubated at $35^{\circ} \mathrm{C}$, rotated at $180 \mathrm{rpm}$ and the reaction time was $3 \mathrm{~h}$.

The effect of substrate concentration on the resolution of MPPD. The effect of substrate concentration on the resolution of MPPD is shown in Fig. 3. The reaction rate increased with an increase in the substrate concentration. However, when the substrate concentration exceeded $180 \mathrm{mmol} \mathrm{L}^{-1}$, the rate decreased sharply from 246.5 to $182.7 \mu \mathrm{mol}(\mathrm{min} \mathrm{g})^{-1}$. There may be two reasons for the decline in the reaction rate. First, when the substrate concentration reached more than $180 \mathrm{mmol}$ $\mathrm{L}^{-1}$, MPPD was not completely dissolved in the solvent. Second, a high concentration of formed monoacetate may increase the viscosity of the reaction system, leading to a decrease in the reaction rate. Meanwhile, the change in concentration had little effect on the enantioselectivity of the enzyme, and the ee value of $S$-diacetates was $99.2 \%$ at $180 \mathrm{mmol} \mathrm{L}^{-1}$.

MPPD enzymatic reaction process curve. According to the results for the resolution of MPPD with CLEAs-YCJ01, the optimum conditions for enzyme catalysis included the use of isopropyl ether as the solvent, MPPD concentration of $180 \mathrm{mmol} \mathrm{L}^{-1}$, molar ratio of vinyl acetate to substrate of $3: 1$,

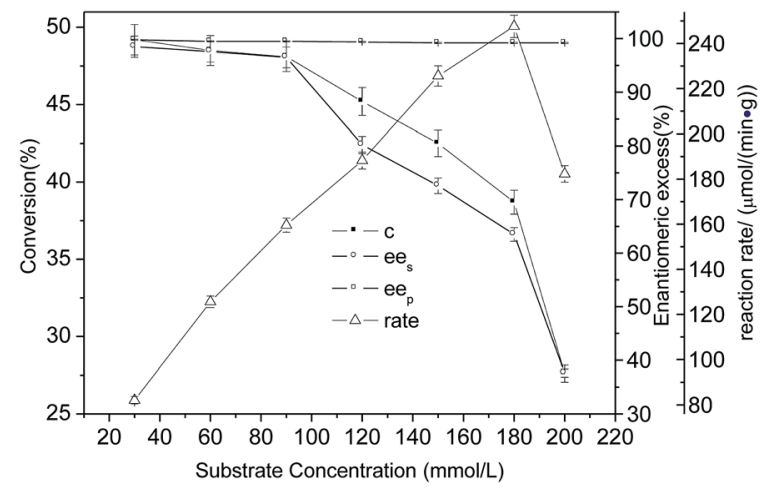

Fig. 3 Effect of substrate concentration on the resolution of MPPD. Reaction conditions: the resolution of MPPD was performed in $20 \mathrm{~mL}$ isopropyl ether containing $20 \mathrm{mg}$ CLEAs-YCJ01 and the molar ratio of MPPD to vinyl acetate was $3: 1$. The mixture was incubated at $35^{\circ} \mathrm{C}$, rotated at $180 \mathrm{rpm}$ with a water content 0.56 , and the reaction time was $6 \mathrm{~h}$. 
reaction temperature of $35{ }^{\circ} \mathrm{C}$ and water content of 0.56 . Under these optimum conditions, the resolution process curve of MPPD with CLEAs-YCJ01 was obtained, as shown in Fig. 4. At the beginning of the reaction, $S$-monoacetate was rapidly transformed into $S$-diacetate. As the reaction progressed further, the substrate concentration gradually decreased, which led to a slow increase in conversion. At the reaction time of $12 \mathrm{~h}$, the yield of $S$-diacetates was $49.9 \%$ and the ee values for monoacetate and $S$-diacetates were $99.1 \%$ and $99.2 \%$, respectively. Thus, excellent ee values were simultaneously obtained for both the $R$ - and $S$-type compounds, and the resolution of MPPD by CLEAs-YCJ01 gave $49.9 \%$ yield for $S$-diacetates and 49.3 yield for $R$-monoacetate.

Operational stability of CLEAs-YCJ01. The operational stabilities of CLEAs-YCJ01 and lipase YCJ01 for the resolution of MPPD are shown in Fig. 5 . When the reaction was catalyzed by CLEAs-YCJ01, the highest conversion and enantioselectivity

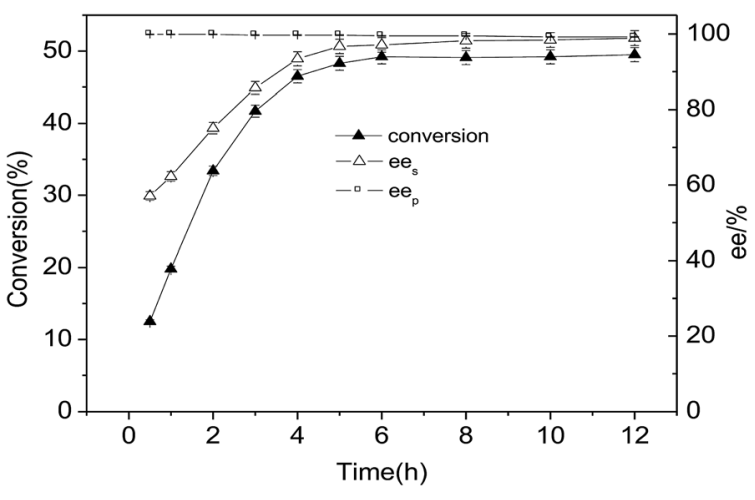

Fig. 4 Time course of resolution of MPPD by CLEAs-YCJ01. Reaction conditions: the resolution of MPPD was performed in $20 \mathrm{~mL}$ isopropyl ether containing $180 \mathrm{mM}$ MPPD, $540 \mathrm{mM}$ vinyl acetate and $20 \mathrm{mg}$ CLEAs lipase YCJ01. The mixture was incubated at $35^{\circ} \mathrm{C}$ and rotated at $180 \mathrm{rpm}$ with a water content of 0.56 .

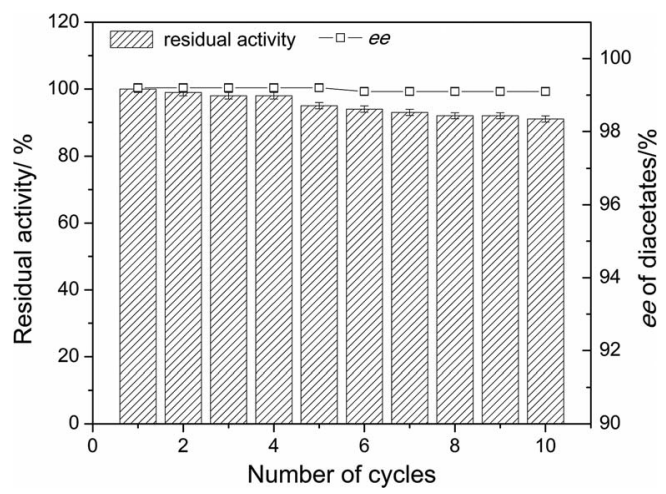

Fig. 5 Operational stabilities of the lipase YCJ01 and CLEAs-YCJ01. Reaction conditions: the resolution of MPPD was performed in $20 \mathrm{~mL}$ isopropyl ether containing $180 \mathrm{mM}$ MPPD, $540 \mathrm{mM}$ vinyl acetate and $20 \mathrm{mg} \mathrm{CLEAs}-\mathrm{YCJ} 01$. The mixture was incubated at $35^{\circ} \mathrm{C}$ and rotated at $180 \mathrm{rpm}$ with a water content 0.56 . Residual activity $=$ (the conversion of MPPD/the conversion of MPPD for the first cycle) $\times$ $100 \%$. Operational conditions: the first cycle ended with the conversion of $49.2 \%$ for MPPD at $12 \mathrm{~h}$, and the other cycles ended with the same time of the first cycle. were achieved in the first batch. Thereafter, the activity of lipase YCJ01 decreased. The residual activity of CLEAs-YCJ01 after ten batches remained at $91.2 \%$ of the initial activity, and the ee values of $S$-diacetates remained above $99.0 \%$ after every batch. These results showed that CLEAs-YCJ01 has good operational stability and the reaction time does not change the enantioselectivity of CLEAs-YCJ01, indicating that the two configurations of substrate with high ee values could be achieved by prolonging the reaction time or adding catalyst at every batch reaction.

The methods for the preparation of enantiomerically pure MPPD include asymmetric catalysis and enzyme catalysis. Zhu et al. ${ }^{7}$ applied a chiral nanoporous metal-organic catalyst for the preparation of $S$-MPPD with a substrate concentration of $80 \mathrm{mmol} \mathrm{L}^{-1}$ and the reaction reached $57 \%$ conversion and $87 \%$ ee after $24 \mathrm{~h}$. Bendigiri et al. ${ }^{9}$ reported a recombinant epoxide hydrolase from Yarrowia lipolytica for the preparation of $S$ MPPD and the ee was $95 \%$. Zhao et $a .^{30}$ applied an epoxide hydrolase for the preparation of $R$-MPPD and the ee was $73 \%$. Theil et al. ${ }^{15}$ reported a transformation in the presence of Amano lipase PS from B. cepacia, in which the yield of $S$-diacetates reached $42 \%$ and the ee for $S$-diacetates was $93 \%$. In the above studies, the concentration of substrate was in the range of 10-80 $\mathrm{mmol} \mathrm{L}^{-1}$. In this work, a high enantioselectivity of $S$ diacetates and substrate concentration were obtained using CLEAs-YCJ01 as a catalyst. The ee values for monoacetate and $S$ diacetates were $99.1 \%$ and $99.2 \%$, respectively, and the substrate concentration reached $180 \mathrm{mmol} \mathrm{L}^{-1}$, which shows potential prospects for industrial applications.

\section{Resolution of 3-aryloxy-1,2-propanediols by CLEAs-YCJ01}

Since CLEAs-YCJ01 showed excellent enantioselectivity towards MPPD, it was evaluated for the resolution of a series of 3-aryloxy1,2-propanediols (six analogues of MPPD). The reactions are shown in Scheme 1 and the results are shown in Table 5. Every $S$-monoacetate of 3-aryloxy-1,2-propanediols preferentially transformed into $S$-diacetates with a high conversion ( $\geq 49.3 \%$ ), favorable ee values $(94.8-99.4 \%)$ for $S$-diacetates and high ee values (92.1-99.2\%) for $R$-monoacetate. This means that CLEAsYCJ01 has relatively strict enantioselectivity towards all the tested 3-aryloxy-1,2-propanediols. Especially, CLEAs-YCJ01 had strict enantioselectivity towards 3-(4-methylphenoxy)-1,2propanediol (substrate 2, Table 5), and the ee values for monoacetate and $S$-diacetates were $99.1 \%$ and $99.2 \%$, respectively. Also, $99.2 \%$ ee of monoacetate and $99.4 \%$ ee of $S$-diacetates were obtained for 3-phenoxy-1,2-propanediol (substrate 1, Table 5) by CLEAs-YCJ01.

The six types of 3-aryloxy-1,2-propanediols have the common structure of 3-phenoxy-1,2-propanediols with different substituents on their benzene ring. As shown in Table 5, substrate 4 has an ortho benzene methyl moiety and substrate 6 has a para benzene methyl moiety. CLEAs-YCJ01 showed different enantioselectivities to these two substrates. Overall, the substrates having a para substituent on the benzene ring did not greatly affect the enantioselectivity, while that having an ortho substituent showed a large enantioselective effect. It may be possible that the ortho substitution of the substrate near the 
Table 5 Resolution of racemic 3-aryloxy-1,2-propanediols in non-aqueous solvents ${ }^{a}$

\begin{tabular}{|c|c|c|c|c|c|c|}
\hline \multirow[b]{2}{*}{ No. } & \multirow[b]{2}{*}{ Substrate } & \multirow[b]{2}{*}{ Catalyst } & \multicolumn{2}{|l|}{ ee } & \multirow[b]{2}{*}{$c(\%)$} & \multirow[b]{2}{*}{$E$} \\
\hline & & & Monoacetate & Diacetates & & \\
\hline 1 & & $\begin{array}{l}\text { Lipase YCJ01 } \\
\text { CLEAs-YCJ01 }\end{array}$ & $\begin{array}{l}78.5 \pm 1.0 \\
99.2 \pm 0.1\end{array}$ & $\begin{array}{l}99.1 \pm 0.1 \\
99.4 \pm 0.1\end{array}$ & $\begin{array}{l}44.2 \pm 0.3 \\
49.9 \pm 0.1\end{array}$ & $\begin{array}{c}529 \pm 12 \\
1836 \pm 132\end{array}$ \\
\hline 2 & & $\begin{array}{l}\text { Lipase YCJ01 } \\
\text { CLEAs-YCJ01 }\end{array}$ & $\begin{array}{l}83.4 \pm 1.0 \\
99.1 \pm 0.1\end{array}$ & $\begin{array}{l}99.1 \pm 0.1 \\
99.2 \pm 0.1\end{array}$ & $\begin{array}{l}45.7 \pm 0.3 \\
49.9 \pm 0.1\end{array}$ & $\begin{array}{r}601 \pm 18 \\
1347 \pm 78\end{array}$ \\
\hline 3 & & $\begin{array}{l}\text { Lipase YCJ01 } \\
\text { CLEAs-YCJ01 }\end{array}$ & $\begin{array}{l}57.8 \pm 1.0 \\
95.2 \pm 0.1\end{array}$ & $\begin{array}{l}96.2 \pm 0.6 \\
96.0 \pm 0.2\end{array}$ & $\begin{array}{l}37.5 \pm 0.3 \\
49.8 \pm 0.1\end{array}$ & $\begin{array}{r}94 \pm 18 \\
184 \pm 21\end{array}$ \\
\hline 4 & & $\begin{array}{l}\text { Lipase YCJ01 } \\
\text { CLEAs-YCJ01 }\end{array}$ & $\begin{array}{l}44.8 \pm 1.6 \\
92.1 \pm 0.2\end{array}$ & $\begin{array}{l}94.4 \pm 0.7 \\
94.8 \pm 0.2\end{array}$ & $\begin{array}{l}32.2 \pm 0.6 \\
49.3 \pm 0.1\end{array}$ & $\begin{array}{c}54 \pm 9 \\
124 \pm 11\end{array}$ \\
\hline 5 & & $\begin{array}{l}\text { Lipase YCJ01 } \\
\text { CLEAs-YCJ01 }\end{array}$ & $\begin{array}{l}60.4 \pm 1.4 \\
95.2 \pm 0.2\end{array}$ & $\begin{array}{l}95.4 \pm 0.5 \\
95.3 \pm 0.2\end{array}$ & $\begin{array}{l}38.8 \pm 0.4 \\
49.9 \pm 0.1\end{array}$ & $\begin{array}{r}78 \pm 12 \\
156 \pm 11\end{array}$ \\
\hline 6 & & $\begin{array}{l}\text { Lipase YCJ01 } \\
\text { CLEAs-YCJ01 }\end{array}$ & $\begin{array}{l}74.5 \pm 1.8 \\
95.6 \pm 0.2\end{array}$ & $\begin{array}{l}96.7 \pm 0.1 \\
96.5 \pm 0.2\end{array}$ & $\begin{array}{l}43.5 \pm 0.7 \\
49.8 \pm 0.1\end{array}$ & $\begin{array}{l}137 \pm 16 \\
219 \pm 17\end{array}$ \\
\hline
\end{tabular}

catalytic active center slightly affects the substrate orientation in the active center, thus reducing the enantioselectivity of the enzyme towards ortho-substituted compound-lipase complexes. ${ }^{15}$

Theil's group ${ }^{\mathbf{1 4 , 1 5}}$ used Amano lipase PS to resolve 3-aryloxy1,2-propanediols. The ee values of $R$-type compounds ranged from $55 \%$ to $99.8 \%$, while that of $S$-type compounds ranged from $79 \%$ to $96.8 \%$. In summary, CLEAs-YCJ01 showed good enantioselectivity towards 3-aryloxy-1,2-propanediols with high ee values for both $R$ - and $S$-type compounds, indicating that CLEAs-YCJ01 has relatively strict substrate selectivity towards all the used analogues of MPPD.

\section{Experimental}

\section{Materials}

The lipase YCJ01 from $B$. ambifaria was characterized in our previous report, and its amino acid sequence was assigned GenBank accession no. JQ733583. B. ambifaria YCJ01 was deposited in CCTCC (Wuhan, China) with the accession number CCTCC M 2011058. ${ }^{18}$ 3-Aryloxy-1,2-propanediols were purchased from Heowns Biochemical Technology LLC (Tianjin, China). $p$-Nitrophenyl palmitate ( $p$ NPP) was purchased from Sigma-Aldrich (St. Louis, MO, USA). Vinyl acetate, isopropyl ether and all other chemicals were purchased from Sinopharm Chemical Reagent Co., Ltd. (Shanghai, China). All reagents were used directly without any further treatment.

\section{Enzyme activity assay}

The hydrolytic activity of the free lipase was assayed according to reported literature procedures and $p$ NPP was used as the substrate. ${ }^{31}$ CLEAs-YCJ01 was suspended in phosphate buffer $(\mathrm{pH}=7.5,50 \mathrm{mM})$ and samples of this suspension were used to calculate its activity according to the procedure reported for the free enzyme.

\section{Transesterification reaction}

The enzymatic transesterification reactions were performed in $50 \mathrm{~mL}$ conical flasks with stoppers. The appropriate amounts of solvent, 3-aryloxy-1,2-propanediols, vinyl acetate, and enzyme were introduced into the conical flasks and incubated at a constant temperature and shaking at $180 \mathrm{rpm}$. Aliquots of samples $(30 \mu \mathrm{L})$ were withdrawn from the reaction mixture at intervals and the samples were analyzed via high-performance liquid chromatography (HPLC) according the following method.

\section{Analytical methods}

The reaction mixture was sampled at intervals and the solvent in each sample was volatilized and the remains were redissolved in a mobile phase composed of $n$-hexane/isopropanol $(85 / 15, \mathrm{v} /$ v) $(200 \mu \mathrm{L})$ then filtered using a $0.45 \mu \mathrm{m}$ membrane filter. After filtration, the treated samples were analyzed via HPLC using a Chiralcel® OD-H column (Daicel, $4.6 \times 250 \mathrm{~mm}$ ) and detected 
at the ultraviolet wavelength of $270 \mathrm{~nm}$. The mobile phase flow

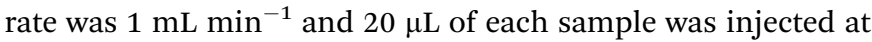
$30{ }^{\circ} \mathrm{C}$. The retention times of all the substrates are presented in the ESI. $\dagger$

The ee values of $R$-monoacetate $\left(\mathrm{ee}_{\mathrm{s}}\right)$ and $S$-diacetates $\left(\mathrm{ee}_{\mathrm{p}}\right)$ were calculated by HPLC. The yield of $S$-diacetates was determined by HPLC. The conversion of 3-aryloxy-1,2-propanediols (c) was calculated as $c(\%)=\mathrm{ee}_{\mathrm{s}} /\left(\mathrm{ee}_{\mathrm{s}}+\mathrm{ee}_{\mathrm{p}}\right) \times 100$ and the enantioselectivity $(E)$ was calculated as $E=\ln \left[(1-c)\left(1-\mathrm{ee}_{\mathrm{s}}\right) /(1\right.$ $\left.-c)\left(1+\mathrm{ee}_{\mathrm{s}}\right)\right]$.

\section{Water content}

The substrates and solvents were separately pre-equilibrated at different water contents $\left(a_{\mathrm{w}}\right)$ prior to the resolution. All samples were placed in a closed vessel above saturated salts, and equilibrium was reached for $48 \mathrm{~h}$ at room temperature. The salts used in this test included LiCl, $a_{\mathrm{w}}=0.11 ; \mathrm{CH}_{3} \mathrm{COOK}, a_{\mathrm{w}}=0.24$; $\mathrm{MgCl}_{2}, a_{\mathrm{w}}=0.33 ; \mathrm{Mg}\left(\mathrm{NO}_{3}\right)_{2}, a_{\mathrm{w}}=0.56$, and NaCl, $a_{\mathrm{w}}=0.75$.

\section{Preparation of CLEAs of lipase YCJ01 (CLEAs-YCJ01)}

The preparation of CLEAs-YCJ01 in this work was done according to the procedures described by Schoevaart $^{20}$ with some modifications. Crude lipase YCJ01 powder was prepared in our previous work ${ }^{\mathbf{1 8}}$ and dissolved in phosphate buffer $(\mathrm{pH}=$ 7.5 and $0.05 \mathrm{M}$ ) to a concentration of $1.2 \mathrm{mg}$ protein per $\mathrm{mL}$ (53 $\mathrm{U})$. Aggregates of lipase YCJ01 were prepared using precipitants and glutaraldehyde was added to a total concentration of $0.25 \%$ $(\mathrm{v} / \mathrm{v})$, then the resulting suspensions were stirred at $0{ }^{\circ} \mathrm{C}$ for $4 \mathrm{~h}$. The CLEAs of lipase YCJ01 was separated by centrifugation and obtained by volatilizing the residual solvent. All portions of the filtrate were retained for the determination of protein concentration and activity.

\section{Bioconversion and determination of operational stability}

In a typical reaction, $20 \mathrm{~mL}$ isopropyl ether, CLEAs-YCJ01 (20 $\mathrm{mg})$, MPPD (50 mM), and vinyl acetate $(100 \mathrm{mM})$ were loaded into $50 \mathrm{~mL}$ conical flasks with stoppers. The mixture was kept at $35{ }^{\circ} \mathrm{C}$ and rotated at $180 \mathrm{rpm}$. The samples were withdrawn from the mixture and analyzed by HPLC, as described above. When the determination of operational stability was performed, the filtered CLEAs-YCJ01 was washed with fresh isopropyl ether $(3 \times 5 \mathrm{~mL})$ and loaded back into the conical flasks for the next cycle.

\section{Conclusions}

In this work, cross-linked enzyme aggregates of lipase YCJ01 (CLEAs-YCJ01) were prepared with $t$-butanol as the precipitant, and $214.8 \%$ of activity recovery was achieved. CLEAs-YCJ01 showed excellent enantioselectivity towards 3-(4methylphenoxy)-1,2-propanediol with ee values of $99.2 \%$ for $S$ diacetates and $99.1 \%$ for monoacetate. For the first time, $R$ - and $S$-type compounds with excellent ee values were simultaneously obtained. CLEAs-YCJ01 also showed high operational stability and maintained $91.2 \%$ residual activity after ten batches. These results showed that CLEAs-YCJ01 has good operational stability and the reaction time does not change the enantioselectivity of CLEAs-YCJ01, indicating that the two configurations of substrate with high ee values could be achieved by prolonging the reaction time or adding catalyst at every batch reaction.

Further, CLEAs-YCJ01 was evaluated for the resolution of a series of 3-aryloxy-1,2-propanediols (six analogues of MPPD) under the optimized reaction conditions for the resolution of MPPD. The results showed that CLEAs-YCJ01 has relatively strict enantioselectivity towards 3-aryloxy-1,2-propanediols with a high yield ( $\geq 49.3 \%$ ), favorable ee values $(94.8-99.4 \%$ ) for $S$ diacetates and high ee values (92.1-99.2\%) for $R$-monoacetate. Especially, towards 3-(4-methylphenoxy)-1,2-propanediol and 3phenoxy-1,2-propanediol, both of $R$ - and $S$-type compounds with $>99 \%$ ee were obtained.

\section{Conflicts of interest}

There are no conflicts to declare.

\section{Acknowledgements}

This work was supported by the National High Technology Research and Development Key Program of China (2012AA022205).

\section{Notes and references}

1 H.-S. Byun, J. A. Sadlofsky and R. Bittman, J. Org. Chem., 1998, 63, 2560-2563.

2 S. Maccari, M. Buoncervello, A. Rampin, M. Spada, D. Macchia, L. Giordani, T. Stati, C. Bearzi, L. Catalano, R. Rizzi, L. Gabriele and G. Marano, Br. J. Pharmacol., 2017, 174, 139-149.

3 B. Liu, X. Qian, Q. Wu and X. Lin, Enzyme Microb. Technol., 2008, 43, 375-380.

4 B. L. Linhares, N. R. F. Nascimento, L. F. Gonzaga-Silva, C. F. Santos, M. O. Moraes, L. B. Marinho, A. P. G. Silva, M. C. Fonteles and R. Reges, Eur. J. Pharmacol., 2018, 833, 425-431.

5 J. Agustian, A. H. Kamaruddin and S. Bhatia, Process Biochem., 2010, 45, 1587-1604.

6 A. Y. Ridwan, R. Matoba, J. Wu, J.-H. Choi, H. Hirai and H. Kawagishi, Tetrahedron Lett., 2018, 59, 2559-2561.

7 C. Zhu, G. Yuan, X. Chen, Z. Yang and Y. Cui, J. Am. Chem. Soc., 2012, 134, 8058-8061.

8 M. T. Reetz, M. Bocola, L.-W. Wang, J. Sanchis, A. Cronin, M. Arand, J. Zou, A. Archelas, A.-L. Bottalla, A. Naworyta and S. L. Mowbray, J. Am. Chem. Soc., 2009, 131, 7334-7343.

9 C. Bendigiri, K. Harini, S. Yenkar, S. Zinjarde, R. Sowdhamini and A. RaviKumar, RSC Adv., 2018, 8, 12918-12926.

10 Z. Sun, L. Wu, M. Bocola, H. C. S. Chan, R. Lonsdale, X.-D. Kong, S. Yuan, J. Zhou and M. T. Reetz, J. Am. Chem. Soc., 2018, 140, 310-318.

11 Å. Janfalk Carlsson, P. Bauer, H. Ma and M. Widersten, Biochemistry, 2016, 55, 1940. 
12 Z. S. Seddigi, M. S. Malik, S. A. Ahmed, A. O. Babalghith and A. Kamal, Coord. Chem. Rev., 2017, 348, 54-70.

13 X. Tian, G.-W. Zheng, C.-X. Li, Z.-L. Wang and J.-H. Xu, J. Mol. Catal. B: Enzym., 2011, 73, 80-84.

14 F. Theil, J. Weidner, S. Ballschuh, A. Kunath and H. Schick, Tetrahedron Lett., 1993, 34, 305-306.

15 F. Theil, J. Weidner, S. Ballschuh, A. Kunath and H. Schick, J. Org. Chem., 1994, 59, 388-393.

16 S. Cao, P. Xu, Y. Ma, X. Yao, Y. Yao, M. Zong, X. Li and W. Lou, Chin. J. Catal., 2016, 37, 1814-1823.

17 S. Talekar, A. Joshi, G. Joshi, P. Kamat, R. Haripurkar and S. Kambale, RSC Adv., 2013, 3, 12485-12511.

18 C. Yao, Y. Cao, S. Wu, S. Li and B. He, J. Mol. Catal. B: Enzym., 2013, 85-86, 105-110.

19 J. Skjold-Jørgensen, J. Vind, A. Svendsen and M. J. Bjerrum, Biochemistry, 2014, 53, 4152-4160.

20 R. Schoevaart, M. W. Wolbers, M. Golubovic, M. Ottens, A. P. Kieboom, F. van Rantwijk, L. A. van der Wielen and R. A. Sheldon, Biotechnol. Bioeng., 2004, 87, 754-762.

21 M. Agarwal, P. K. Dikshit, J. B. Bhasarkar, A. J. Borah and V. S. Moholkar, Chem. Eng. J., 2016, 295, 254-267.
22 J. Abildskov, M. B. van Leeuwen, C. G. Boeriu and L. A. M. van den Broek, J. Mol. Catal. B: Enzym., 2013, 8586, 200-213.

23 M. D. Alves, F. M. Aracri, É. C. Cren and A. A. Mendes, Chem. Eng. J., 2017, 311, 1-12.

24 T. Miyazawa, S. Kurita, S. Ueji and T. Yamada, Biocatal. Biotransform., 2009, 17, 459-473.

25 V. Athawale, N. Manjrekar and M. Athawale, Biotechnol. Prog., 2003, 19, 298-302.

26 M. Z. Kamal, P. Yedavalli, M. V. Deshmukh and N. M. Rao, Protein Sci., 2013, 22, 904-915.

27 B. Wang, C. Zhang, Q. He, H. Qin, G. Liang and W. Liu, Mol. Catal., 2018, 448, 116-121.

28 H. Cao, L. Deng, M. Lei, F. Wang and T. Tan, J. Mol. Catal. B: Enzym., 2014, 109, 101-108.

29 R. Sato, A. Sato and H. Tokuyama, J. Appl. Polym. Sci., 2015, 132, 1-5.

30 J. Zhao, Y.-Y. Chu, A.-T. Li, X. Ju, X. Kong, J. Pan, Y. Tang and J.-H. Xu, Adv. Synth. Catal., 2011, 353, 1510-1518.

31 B. Wang, W. Li, B. Wu and B. He, J. Mol. Catal. B: Enzym., 2014, 106, 105-110. 